\title{
Effects of metformin on polycystic ovary syndrome: a randomized, double-blind, placebo-controlled study
}

\author{
Nazma-Akhtar ${ }^{1 *}$, Hurjahan-Banu ${ }^{2}$, Md. Shahed-Morshed ${ }^{3}$, Tania-Sultana ${ }^{4}$, Afroza-Begum ${ }^{5}$, MA Hasanat ${ }^{2}$ \\ ${ }^{1}$ Shahid Tajuddin Ahmad Medical College, Gazipur, Bangladesh; ${ }^{2}$ Department of Endocrinology, \\ Bangabandhu Sheikh Mujib Medical University, Dhaka, Bangladesh; ${ }^{3}$ Department of Emergency, Kurmitola \\ General Hospital, Dhaka, Bangladesh; ${ }^{4}$ Department of Medicine, Dhaka Dental College Hospital, Dhaka, \\ Bangladesh; ${ }^{5}$ Department of Endocrinology, Dhaka Medical College Hospital, Dhaka, Bangladesh
}

\begin{abstract}
Background and objectives: Metformin improves manifestations of polycystic ovary syndrome (PCOS) by reducing insulin resistance. The objective of this study was to determine how metformin, in combination with lifestyle changes, affects the clinical manifestations of PCOS.
\end{abstract}

\begin{abstract}
Materials and Methods: Patients with PCOS attending the outpatient of a tertiary care hospital were enrolled in the study. Revised Rotterdam Consensus 2003 criteria were used to diagnose cases of PCOS. Clinical information, anthropometric measurement, serum progesterone and polycystic ovarian morphology (PCOM) of each subject were recorded in a prescribed data sheet at baseline and after a period of nine months. Randomized placebo controlled double blind design was used to assign participants in respective groups. Participants were randomly assigned to receive 9 month course of either metformin (1500 mg/day) or placebo. Both groups were advised regarding schedule of lifestyle modification. Outcome variables were clinical manifestations related to metabolic, reproductive and androgenic status of PCOS.
\end{abstract}

Results: Out of 80 enrolled PCOS cases, 49 completed the study (metformin=26, placebo=23). The mean age of the study participants of metformin and placebo groups was $23.52 \pm 5.18$ and $22.09 \pm 3.58$ years respectively $(p=0.262)$. Menstrual cycle significantly improved in both the study groups (before vs. after - metformin: $19.2 \%$ vs. $76.9 \%, p=0.003$; placebo: $19.2 \%$ vs. $47.8 \%$, $\mathrm{p}=0.02)$ after 9 months, but compared to placebo group no such significant $(p=0.12)$ improvement occurred in metformin group. Severity of hirsutism, presence of acne, serum progesterone level and ovulatory status improved significantly in both groups after completion of the study. Except acanthosis nigricans, other metabolic manifestations did not significantly improve in metformin compared to placebo group after the intervention. While comparing the percentage changes, body mass index (BMI) and waist circumference (WC) reduced significantly in metformin than placebo group (BMI in $\mathrm{kg} / \mathrm{m}^{2}-$ metformin vs. placebo: $-3.63 \pm 8.22$ vs. $+1.42 \pm 6.67, p=0.024$; WC in $\mathrm{cm}-2.81 \pm 7.74$ vs. $+1.68 \pm 7.89, \mathrm{p}=0.05$ ). No significant adverse event was observed in metformin group.

Conclusion: Metformin, in conjunction with lifestyle modifications, has favorable impacts on clinical manifestations of PCOS.

IMC J Med Sci 2021; 15(2): 001

\section{Introduction}

Polycystic ovarian syndrome (PCOS) is a common endocrine disorder of women of reproductive age.
The prevalence of PCOS has been reported between 2 to $19.9 \%$ in different population of the world using different diagnostic criteria [1-11]

*Correspondence: Nazma-Akhtar, Shahid Tajuddin Ahmad Medical College, Gazipur, Bangladesh. Email: nazma.akhtar@ymail.com 
PCOS has been associated with the risk of type 2 diabetes mellitus (T2DM) and metabolic syndrome [12]. Insulin resistance and obesity are the common features seen in PCOS women. About $60-70 \%$ and up to $88 \%$ women with PCOS are reported to have insulin resistance and obesity respectively [13]. Recent evidences have shown an important implication of insulin resistance in the pathogenesis of PCOS irrespective of obesity or over weight $[14,15]$. So, the presence of insulin resistance has prompted widespread use of insulin sensitizing agents in the treatment of PCOS [16]. Among the insulin sensitizers, metformin is the most commonly used agent for the treatment of PCOS [17]. In PCOS patients, metformin has been reported to act by restoring ovulation, and by reducing the weight, circulating androgen levels, risk of miscarriage and gestational diabetes mellitus [13]. Metformin is more effective in reducing hirsutism also [18]. Pioglitazone, another widely used insulin sensitizer, is more effective in reducing menstrual irregularity and ovulation (odds ratio= 2.31) than metformin, but associated with weight gain. Apart from the use of insulin sensitizing agents, lifestyle modifications also have therapeutic value in the management of clinical manifestations of PCOS. It helps especially in reduction of weight, waist circumference and hirsutism [19]. Combination effects of lifestyle modification and insulin sensitizer have been reported to be better than each modality of treatment alone especially in reducing body mass index (BMI) and improving menstrual irregularity [20]. In view of the above, the present study was undertaken to determine whether metformin or placebo, in conjunction with lifestyle changes, could affect the clinical manifestations of patients with PCOS.

\section{Materials and methods}

The research protocol was approved by the Institutional Review Board (IRB) of BSMMU (No.BSMMU/2014/05). Informed written consent was obtained from all participants. At the end of the study period, PCOS patients in placebo group were offered treatment with metformin based on the study findings.
Study type and population: This randomized double blind placebo-controlled study was conducted at the Department of Endocrinology of Bangabandhu Sheikh Mujib Medical University, Dhaka, Bangladesh. Patients with PCOS attending the outpatient clinic of Endocrinology department were enrolled. Diagnosis of PCOS was based on Revised Rotterdam Consensus 2003 criteria [21]. Patients with significant hyperprolactinemia (prolactin $>25 \mathrm{ng} / \mathrm{ml}$ ), abnormal thyroid function tests (thyroid stimulating hormone level - outside the normal reference), congenital adrenal hyperplasia and patients under medications that likely to influence hormonal profiles were excluded. Anyone wishing to have pregnancy was also excluded. Sample size was calculated by $\left[n=2 \sigma^{2}\right.$ $\left.\left(Z_{\alpha}+Z_{\beta}\right)^{2} /\left(\mu_{1}-\mu_{2}\right)^{2}\right]$ formula based on the mean $\pm S D$ changes of BMI from a similarly designed study [22].

Intervention: After confirmation of diagnosis, patients were randomly allocated to either metformin or placebo group by lottery method in a double blind process. Both groups were provided advice regarding schedule of lifestyle modification. Each patient was advised regarding lifestyle modifications that included a weight-based diet [calorie calculated (weight maintenance Kcal \pm 500 Kcal) and diet chart provided], brisk walking for at least 30 minutes at least five days a week and behavioral modification as appropriate [23]. Metformin was prescribed as $1500 \mathrm{mg} /$ day in three divided doses for 9 months. Each tablet of metformin contained metformin $\mathrm{HCl}$ BP $500 \mathrm{mg}$, along with inactive ingredients of povidone, microcrystalline cellulose, croscarmellose sodium and magnesium stearate as excipient. Placebo tablet contained all the ingredients of excipient except metformin. Both metformin and placebo tablets were coded and dispensed in identical blister package.

Follow-up schedule: Each patient was scheduled for five visits within a period of nine months whereupon a window period of 14 days was permitted for the $2^{\text {nd }}$ to $5^{\text {th }}$ visits. In each follow up visit, patients were asked about the practice of lifestyle modification schedules and intake of investigational product (IP). Patients who did not follow all the schedules of lifestyle modifications at least five days a week were considered as noncompliant. Similarly, they were also asked to 
bring the empty blisters of the IP. The blisters were counted and the participants who missed to take $\geq 5 \%$ of the IP were also labeled as noncompliant. Noncompliant participants were excluded from final analysis.

Outcome variables: The main outcome variables were metabolic (BMI, WC, blood pressure), reproductive (menstrual cycle, ovulation by progesterone level and polycystic ovarian morphology) and androgenic (modified FerrimanGallwey score and acne and acanthosis nigricans) manifestations of PCOS. Weight (kilogram) and height (meter) were measured by calibrated bathroom scale and mounted measuring tape respectively to calculate $\mathrm{BMI}\left(\mathrm{kg} / \mathrm{m}^{2}\right)$. Waist circumference (in centimeter) was measured by measuring tape at the level of umbilicus. Asian criteria was used to categorize BMI as under nutrition, optimal, overweight and obese by the cut-offs values of 18.5, 23 and $25 \mathrm{~kg} / \mathrm{m}^{2}$ respectively, and WC by the cut-off value of $80 \mathrm{~cm}$ [24]. Blood pressure was measured by calibrated sphygmomanometer $(\mathrm{mm}-\mathrm{Hg})$ and was categorized by metabolic syndrome criteria (cut-off of 130/85 $\mathrm{mm}-\mathrm{Hg}$ ) [25]. Hirsutism was measured by using modified Ferriman-Gallway (mFG) score and classified into mild, moderate and severe with the total score of $8-15,16-25$ and $\geq 26$ respectively [26]. Acne was observed over face. Acanthosis nigricans was checked on neck, axilla and groin. Missing of at least three menstrual periods in a row was labeled as amenorrhea and without menstruation regularly for more than 35 days termed as oligomenorrhea. Menstruation occurring for consecutive two months was considered as regular menstruation.

Investigations: Blood samples from each participant were collected aseptically for biochemical investigations at the time of enrollment and after nine months. Fasting blood glucose (FBG) was measured by glucose oxidase method and serum luteinizing hormone (LH), follicle stimulating hormone (FSH), total testosterone (TT), and progesterone were measured by chemiluminescent microparticle immunoassay at diagnosis during follicular phase of menstrual cycle. Serum progesterone $\geq 5 \mathrm{ng} / \mathrm{ml}$ was considered as indication of ovulation [27]. Ultrasonogram
(TOSHIBA Aplio 500 imaging machine) was done by trans-abdominal or trans-vaginal route depending on the marital status of the patient during follicular phase of menstrual cycle by skilled sonologists.

Data recording: A standardized questionnaire was used to obtain information regarding the age, personal and family history, obstetric, menstrual and gynecological history, medical diseases, and medications. Clinical information, anthropometric measurement, results of biochemical tests and polycystic ovarian morphology (PCOM) of each subject were recorded in a prescribed data sheet at baseline and after nine months during the last follow up visit $\left(4^{\text {th }}\right)$. Compliance and side-effects were recorded in all the follow up visits.

Data analysis: All data were processed by the SPSS program (version: 22.0). Values were expressed as frequencies (\%) or mean \pm SD or median (interquartile range, IQR). Nominal variables namely occupation, personal and family history, acne, acanthosis nigricans, WC, BP and ovulation categories, inference of ultrasonography findings and side-effects at each visit were analyzed by using Pearson's Chi square/ Fisher's exact test between groups and McNemer test (two related samples) within each group (intervention: before vs. after). Ordinal variables (menstrual cycle, BMI category and severity of hirsutism) were tested by Chi-square test/Fisher's exact test between groups and Wilcoxon signed ranks test within group. Normally distributed quantitative variables (age, BMI, WC, BP, FBG, biochemical results) were analyzed by independent student's t test between groups and paired-t test within group. Skewed variables (mFG score, progesterone, TSH, prolactin, $\mathrm{LH} / \mathrm{FSH}$ ) were analyzed by Mann-Whitney-U test between groups and Wilcoxon rank sum test within each group. A two-tailed $\mathrm{p}<0.05$ was taken as statistically significant.

\section{Results}

Initially, a total 80 women with PCOS were enrolled in the study. Out of 80, 49 PCOS patients completed the study. After unblinding, it was observed that 26 cases were in metformin group and 23 were in placebo group. Out of the rest 31 cases, 4 participants became pregnant before 
reaching the end point (Metformin $=1$, placebo $=$ $3)$, and 27 were dropped out due to incomplete visit (metformin $=9$, placebo $=9$ ) or noncompliant to lifestyle modification or intake of IP (metformin $=4$, placebo $=5)$ (Figure-1).

The mean age of the total study participants of metformin and placebo groups was $23.52 \pm 5.18$ and $22.09 \pm 3.58$ years respectively $(p=0.262)$. Other baseline characteristics of the two groups were similar with respect to occupation, personal and family history and biochemical parameters (Table 1 ).
Table-2 shows the status of metabolic manifestations in PCOS patients before and 9 months after intervention. Compared to placebo group, the metabolic manifestations, except acanthosis nigricans, did not significantly improve in metformin group 9 months after the intervention. Compared to metformin group, the rate of acanthosis nigricans was significantly higher in placebo group at baseline (metformin vs. placebo: $19.2 \%$ vs. $52.2 \%, p=0.02$ ) and remained significantly higher after the end of intervention also $(7.7 \%$ vs. $39.1 \%, p=0.015)$. BMI $(25.17 \pm 5.62$ vs.

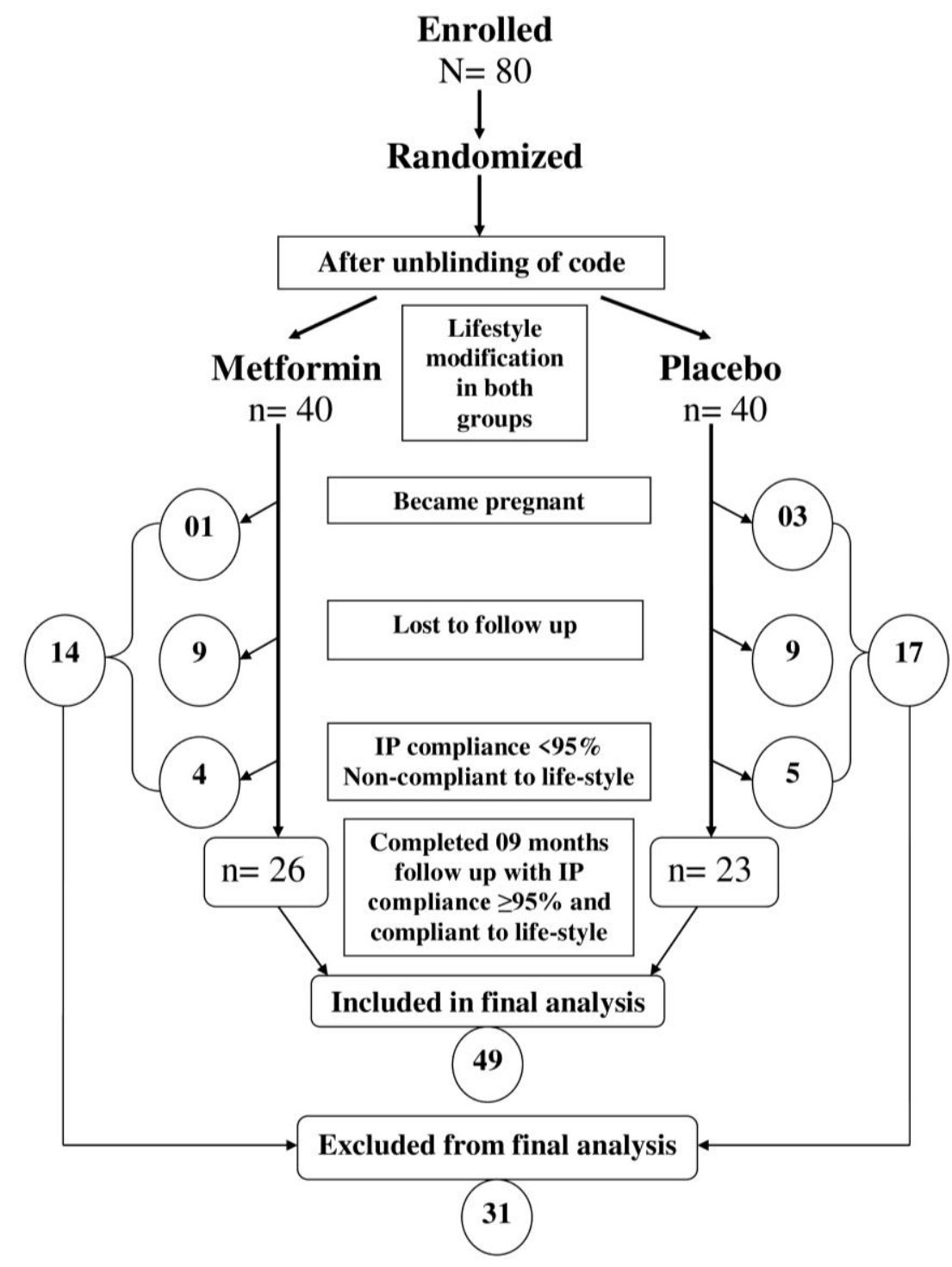

Figure-1: Chart showing the enrollment, intervention and follow up scheme of the study participants. 
Table-1: Baseline characteristics of the study population $(N=49)$

\begin{tabular}{|c|c|c|c|}
\hline Variables & Metformin group & Placebo group & $\mathbf{p}$ \\
\hline Number of participants & 26 & 23 & \\
\hline Age (years), mean $\pm S D$ & $23.52 \pm 5.18$ & $22.09 \pm 3.58$ & $0.262^{\dagger}$ \\
\hline \multicolumn{4}{|l|}{ Occupation, no. (\%) } \\
\hline Housewife & $9(34.6)$ & $8(34.8)$ & \multirow{3}{*}{$1.00^{\pi}$} \\
\hline Service holder & $2(7.7)$ & $1(4.3)$ & \\
\hline Student & $15(57.7)$ & $14(60.9)$ & \\
\hline \multicolumn{4}{|l|}{ Personal history, no. (\%) } \\
\hline Menstrual regulation/abortion & $3(11.5)$ & $2(8.7)$ & $1.00^{\pi}$ \\
\hline Subfertility & $4(15.4)$ & $6(26.1)$ & $0.483^{9}$ \\
\hline \multicolumn{4}{|l|}{ Family history, no. (\%) } \\
\hline Polycystic ovary syndrome & $4(15.4)$ & $1(4.3)$ & $0.353^{9}$ \\
\hline Hirsutism & $6(23.1)$ & $11(47.8)$ & $0.082^{9}$ \\
\hline Subfertility & $3(11.5)$ & $6(26.1)$ & $0.273^{9}$ \\
\hline Obesity & $16(61.5)$ & $17(73.9)$ & $0.382^{\prime \prime}$ \\
\hline Diabetes mellitus & $19(73.1)$ & $19(82.6)$ & $0.506^{n}$ \\
\hline Hypertension & $19(73.1)$ & $20(87.0)$ & $0.299^{\prime \prime}$ \\
\hline \multicolumn{4}{|l|}{ Investigations, mean $\pm S D$} \\
\hline Fasting blood glucose, $\mathrm{mmol} / \mathrm{L}$ & $4.66 \pm 0.43$ & $4.74 \pm 0.44$ & $0.527^{\dagger}$ \\
\hline S. ALT, U/L & $49.58 \pm 16.13$ & $47.87 \pm 21.80$ & $0.755^{\dagger}$ \\
\hline S. creatinine, $\mathrm{mg} / \mathrm{dl}$ & $0.81 \pm 0.13$ & $0.78 \pm 0.16$ & $0.487^{\dagger}$ \\
\hline S. TSH, $\mathrm{mlU} / \mathrm{ml}$ & $2.22 \pm 1.10$ & $2.49 \pm 1.36$ & $0.447^{\dagger}$ \\
\hline S. prolactin, $\mathrm{ng} / \mathrm{ml}$ & $16.14 \pm 21.12$ & $11.12 \pm 5.66$ & $0.275^{\dagger}$ \\
\hline S. LH/FSH ratio & $1.60 \pm 1.25$ & $1.46 \pm 1.12$ & $0.671^{\dagger}$ \\
\hline S. Total testosterone, $\mathrm{ng} / \mathrm{ml}$ & $8.11 \pm 3.98$ & $8.88 \pm 3.10$ & $0.461^{\dagger}$ \\
\hline
\end{tabular}

Note: "Pearson's Chi-square/ Fisher's Exact test was done as appropriate; ${ }^{\dagger}$ Independent-samples $t$ test or *Mann-Whitney $U$ test was done as appropriate

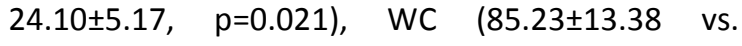
$82.54 \pm 12.90, p=0.046)$, systolic $(110.96 \pm 12.65$ vs. 106.54 $\pm 11.98, p=0.003)$ and diastolic BP $(75.0 \pm 9.06$ vs. $70.38 \pm 8.59, p=0.002$ ) significantly improved in metformin group after intervention while no such changes occurred in placebo group. BMI, WC and BP categories did not improve in either group after 9 months of intervention.

The status of reproductive and androgenic manifestations of the study groups before and after the intervention is shown in Table-3. Before intervention, all the characteristics of both the groups were similar. Menstrual cycle significantly improved in both the study groups (before vs. aftermetformin: $19.2 \%$ vs. $76.9 \%, p=0.003$; placebo: $19.2 \%$ vs. $47.8 \%, p=0.02$ ) after 9 months, but no such significant $(p=0.12)$ improvement occurred in metformin group compared to placebo group. Severity of hirsutism, presence of acne, serum progesterone level and ovulatory status improved significantly in both metformin and placebo groups after 9 months of study period. Only, mFG score, hirsutism, serum progesterone level and ovulatory status (decrease of anovulation rate by $-53.8 \%$ vs. $95.7 \%, p=0.001)$ improved significantly $(p=0.05$, 
Table-2: Metabolic manifestations of the study groups before and after intervention $(N=49)$

\begin{tabular}{|c|c|c|c|c|c|c|c|c|}
\hline \multirow[t]{2}{*}{ Parameters } & \multicolumn{3}{|c|}{ Metformin $(n=26)$} & \multicolumn{3}{|c|}{ Placebo $(n=23)$} & \multicolumn{2}{|c|}{$\begin{array}{c}\text { P values for } \\
\text { Metformin vs. } \\
\text { Placebo }\end{array}$} \\
\hline & Before & After & $\mathbf{p}$ & Before & After & $\mathbf{p}$ & Before & After \\
\hline \multirow[t]{2}{*}{$\mathrm{BMI}, \mathrm{kg} / \mathrm{m}^{2}$ (mean $\left.\pm \mathrm{SD}\right)$} & 25.17 & 24.10 & $0.021 *$ & 25.77 & 25.96 & $0.545^{*}$ & $0.715^{9}$ & $0.226^{\pi}$ \\
\hline & \pm 5.62 & \pm 5.17 & & \pm 5.89 & \pm 5.43 & & & \\
\hline \multicolumn{9}{|l|}{ BMI category, no. (\%) } \\
\hline Underweight & $2(7.7)$ & $2(7.7)$ & & $3(13.0)$ & $2(8.7)$ & & & \\
\hline Optimal & $9(34.6)$ & $8(30.8)$ & $0.206^{\ddagger}$ & $4(17.4)$ & $4(17.4)$ & $0.739^{\ddagger}$ & $0.321^{*}$ & $0.591^{¥}$ \\
\hline Overweight & $3(11.5)$ & $9(34.6)$ & & $3(13.0)$ & $5(21.7)$ & & & \\
\hline Obese & $12(46.2)$ & $7(26.9)$ & & $13(56.5)$ & $12(52.2)$ & & & \\
\hline \multirow[t]{2}{*}{$W C(\mathrm{~cm}$, mean $\pm S D)$} & 85.23 & 82.54 & $0.046 *$ & 84.74 & 85.80 & $0.428 *$ & $0.893^{9}$ & $0.352^{\pi}$ \\
\hline & \pm 13.38 & \pm 12.9 & & \pm 11.88 & \pm 11.24 & & & \\
\hline \multicolumn{9}{|l|}{ WC category, no. (\%) } \\
\hline Non-obese & 7 (26.9) & $11(42.3)$ & $0.219^{\ddagger}$ & $9(39.1)$ & $7(30.4)$ & $0.625^{\ddagger}$ & $0.542^{*}$ & $0.554^{\ddagger}$ \\
\hline Centrally obese & $19(73.1)$ & $15(57.7)$ & & $14(60.9)$ & $16(69.6)$ & & & \\
\hline Systolic BP, & 110.96 & 106.54 & $0.003^{*}$ & 111.96 & 110.87 & $0.487^{*}$ & $0.760^{9}$ & $0.179^{9}$ \\
\hline $\mathrm{mm} \mathrm{Hg}$, mean $\pm S D$ & \pm 12.65 & \pm 11.98 & & \pm 9.62 & \pm 9.96 & & & \\
\hline Diastolic BP, & 75.0 & 70.38 & $0.002 *$ & 73.91 & 72.17 & $0.247^{*}$ & $0.645^{\pi}$ & $0.455^{\natural}$ \\
\hline $\mathrm{mm}-\mathrm{Hg}$, mean $\pm \mathrm{SD}$ & \pm 9.06 & \pm 8.59 & & \pm 7.06 & \pm 7.95 & & & \\
\hline \multicolumn{9}{|l|}{ BP category, no. (\%) } \\
\hline Normal & $23(88.5)$ & $24(92.3)$ & $1.000^{\ddagger}$ & $20(87.0)$ & $22(95.7)$ & $0.500^{\ddagger}$ & $1.00^{*}$ & $1.000^{¥}$ \\
\hline Elevated & $3(11.5)$ & $2(7.7)$ & & $3(13.0)$ & $1(4.3)$ & & & \\
\hline \multicolumn{9}{|l|}{ Acanthosis, no, (\%) } \\
\hline No & $21(80.8)$ & $24(92.3)$ & $0.250^{\ddagger}$ & $11(47.8)$ & $14(60.9)$ & $0.375^{\ddagger}$ & $0.020^{¥}$ & $0.015^{¥}$ \\
\hline Yes & $5(19.2)$ & $2(7.7)$ & & $12(52.2)$ & $9(39.1)$ & & & \\
\hline
\end{tabular}

${ }^{*}$ Paired-T test or +Wilcoxon signed ranks test or ${ }^{7} \mathrm{McNemer}$ test was done to compare within each intervention group. Comparisons between study groups were done by "independent-samples $T$ test or ${ }^{*}$ Pearson's Chi-square/Fisher's exact test

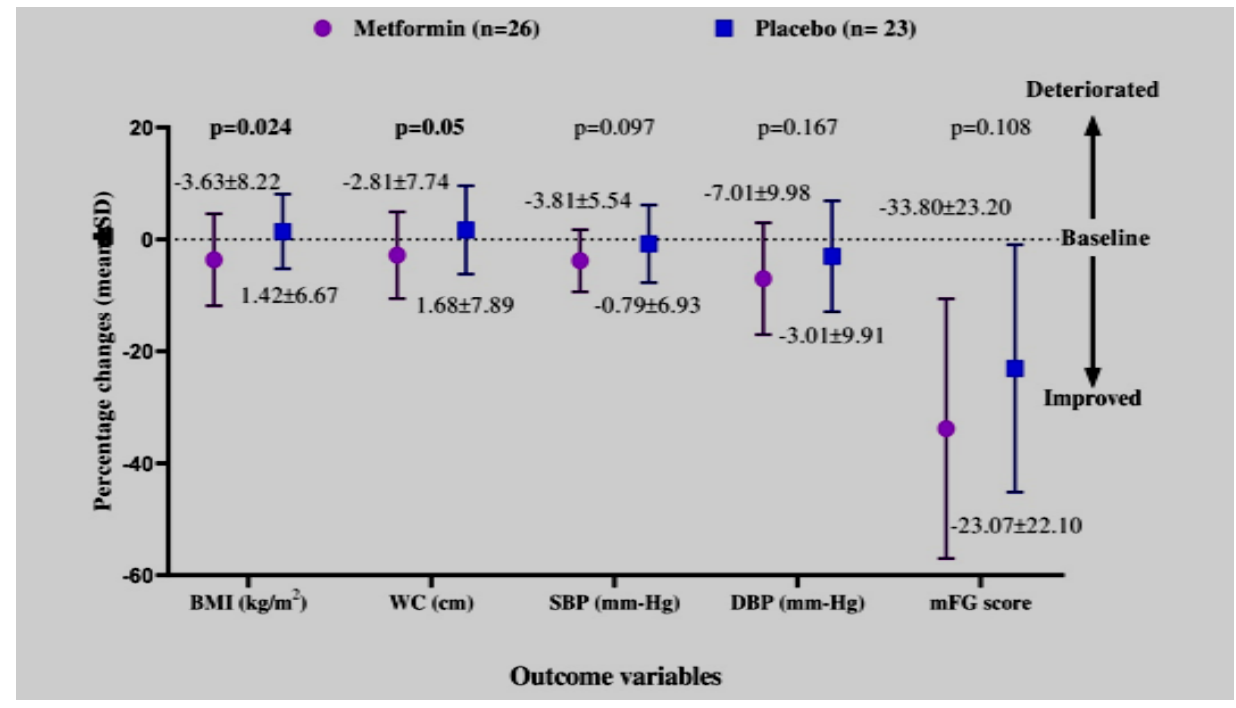

Figure-2: Comparison of percentage changes of clinical manifestations of the study population after the completion of the study from baseline 
Table-3: Reproductive and androgenic manifestations of the study groups before and after intervention $(N=49)$

\begin{tabular}{|c|c|c|c|c|c|c|c|c|}
\hline \multirow[t]{2}{*}{ Parameters } & \multicolumn{3}{|c|}{ Metformin group $(n=26)$} & \multicolumn{3}{|c|}{ Placebo group $(n=23)$} & \multicolumn{2}{|c|}{$\begin{array}{l}\text { Metformin vs. } \\
\text { Placebo ( } p \text { value) }\end{array}$} \\
\hline & Before & After & $p$ & Before & After & $p$ & Before & After \\
\hline \multicolumn{9}{|l|}{ Menstrual cycle } \\
\hline Eumenorrhea & $5(19.2)$ & 20 (76.9) & & $1(19.2)$ & $11(47.8)$ & & & \\
\hline Oligomenorrhea & $18(69.2)$ & $3(11.5)$ & $0.003^{\ddagger}$ & $18(78.3)$ & $7(30.4)$ & $0.020^{\ddagger}$ & $0.297^{*}$ & $0.12^{¥}$ \\
\hline Amenorrhea & $3(11.5)$ & $3(11.5)$ & & $4(17.4)$ & $5(21.7)$ & & & \\
\hline \multirow[t]{2}{*}{ Modified FG score } & 8.15 & 5.15 & $<0.001^{\ddagger}$ & 9.39 & 7.35 & $<0.001^{\ddagger}$ & $0.354^{A}$ & $0.05^{A}$ \\
\hline & \pm 5.20 & \pm 3.99 & & \pm 3.85 & \pm 4.14 & & & \\
\hline \multicolumn{9}{|l|}{$\begin{array}{l}\text { Severity of } \\
\text { hirsutism }\end{array}$} \\
\hline Insignificant & $12(46.2)$ & $22(84.6)$ & & $6(4.3)$ & $12(52.2)$ & & & \\
\hline Mild & $11(42.3)$ & $3(11.5)$ & $0.001^{\ddagger}$ & $16(69.6)$ & $10(43.5)$ & $0.014^{\ddagger}$ & $0.185^{*}$ & $0.021^{¥}$ \\
\hline Moderate & $3(11.5)$ & $1(3.8)$ & & $1(4.3)$ & $1(4.3)$ & & & \\
\hline \multicolumn{9}{|l|}{ Acne } \\
\hline Absent & $17(65.4)$ & $23(88.5)$ & $0.031^{\ddagger}$ & $12(52.2)$ & $18(78.3)$ & $0.031^{\ddagger}$ & $0.394^{¥}$ & $0.448^{*}$ \\
\hline Present & $9(34.6)$ & $3(11.5)$ & & $11(47.8)$ & $5(21.7)$ & & & \\
\hline \multirow{2}{*}{$\begin{array}{l}\text { S. progesterone, } \\
\mathrm{ng} / \mathrm{ml}\end{array}$} & 1.55 & 5.16 & $0.006^{\ddagger}$ & 0.94 & 0.82 & $0.670^{\ddagger}$ & $0.263^{A}$ & $<0.001^{A}$ \\
\hline & \pm 2.58 & \pm 5.20 & & \pm 0.85 & \pm 1.34 & & & \\
\hline \multicolumn{9}{|l|}{ Ovulatory status } \\
\hline Ovulation & $3(11.5)$ & $12(46.2)$ & $0.022^{\ddagger}$ & $0(0.0)$ & $1(4.3)$ & $-^{\ddagger}$ & $0.237^{¥}$ & $0.001^{¥}$ \\
\hline Anovulation & $23(88.5)$ & $14(53.8)$ & & $23(100.0)$ & $22(95.7)$ & & & \\
\hline \multicolumn{9}{|l|}{ PCOM } \\
\hline Absent & $4(15.4)$ & $5(19.2)$ & $1.00^{\ddagger}$ & $2(8.7)$ & $3(13.0)$ & $1.00^{\ddagger}$ & $0.671^{*}$ & $0.706^{¥}$ \\
\hline Present & $22(84.6)$ & $21(80.8)$ & & $21(8.7)$ & $20(87.0)$ & & & \\
\hline
\end{tabular}

Data are expressed as frequency (\%) as appropriate; within parentheses are percentages over column total of respective qualitative variable; FG (Ferriman-Gallwey), PCOM (polycystic ovarian morphology); ${ }^{\ddagger}$ Wilcoxon rank sum test or ${ }^{\ddagger}$ McNemer test was done to compare within each intervention group; Comparisons between study groups were done by ${ }^{A}$ Mann-Whitney $U$ test or ${ }^{*}$ Pearson's Chi-square/Fisher's exact test

$\mathrm{p}=0.021, \mathrm{p}=0.001$, ) in metformin group compared to placebo after 9 months of intervention. PCOM did not improve in either group after 9 months of intervention.

Figure-2 shows the comparison of percentage changes (mean $\pm S D$ ) of clinical manifestations after the completion of the study (9 months) from baseline in metformin and placebo groups. The improvement of $\mathrm{BMI}$ and $\mathrm{WC}$ were significant in metformin than placebo group [metformin vs. placebo- BMI $\left(\mathrm{kg} / \mathrm{m}^{2}\right)$ : $-3.63 \pm 8.22$ vs. $+1.42 \pm 6.67$, $p=0.024 ; W C(\mathrm{~cm}):-2.81 \pm 7.74$ vs. $+1.68 \pm 7.89, p=$ $0.05]$. The SBP, DBP and $\mathrm{mFG}$ score improved in the metformin group but the changes were not statistically significant [metformin vs. placebo- SBP (mm-Hg): $-3.81 \pm 5.54$ vs. $-0.79 \pm 6.93, p=0.097 ; D B P$ (mm-Hg): $-7.01 \pm 9.98$ vs. $-3.01 \pm 9.91, p=0.167 ; \mathrm{mFG}$ : $-33.80 \pm 23.20$ vs. $-23.07 \pm 22.1, p=0.108]$. On subgroup analysis based on BMI classification, both the study groups with $\mathrm{BMI}<23 \mathrm{~kg} / \mathrm{m}^{2}$ gained weight and the percentage changes of BMI was significantly higher in placebo group [metformin $(n=11)$ vs. placebo $(n=7): 0.56 \pm 7.2$ vs. $8.34 \pm 4.30$ 
Table-4: Adverse effects of intervention drugs in the study population $(N=49)$

\begin{tabular}{|c|c|c|c|c|}
\hline \multirow[t]{2}{*}{ Adverse effects } & \multirow[t]{2}{*}{$\begin{array}{l}\text { No. of follow } \\
\text { up visit }\end{array}$} & $\begin{array}{l}\text { Metformin group } \\
(n=26)\end{array}$ & $\begin{array}{l}\text { Placebo group } \\
\quad(n=23)\end{array}$ & \multirow[t]{2}{*}{ P valuet } \\
\hline & & \multicolumn{2}{|c|}{ Number (\%) } & \\
\hline \multirow[t]{4}{*}{ Loose motion } & $1^{\mathrm{st}}$ & $17(65.4)$ & $4(17.4)$ & 0.001 \\
\hline & $2^{\text {nd }}$ & $9(34.6)$ & $6(26.1)$ & 0.552 \\
\hline & $3^{\text {rd }}$ & $10(38.5)$ & $4(17.4)$ & 0.125 \\
\hline & $4^{\text {th }}$ & $4(15.4)$ & $1(4.3)$ & 0.353 \\
\hline \multirow[t]{4}{*}{ Abdominal pain } & $1^{\text {st }}$ & $12(46.2)$ & $8(34.8)$ & 0.562 \\
\hline & $2^{\text {nd }}$ & $9(34.6)$ & $7(30.4)$ & 0.771 \\
\hline & $3^{\text {rd }}$ & $8(30.8)$ & $8(34.8)$ & 1.00 \\
\hline & $4^{\text {th }}$ & $5(19.2)$ & $2(8.7)$ & 0.424 \\
\hline \multirow[t]{4}{*}{ Nausea } & $1^{\text {st }}$ & $11(42.3)$ & $5(21.7)$ & 0.143 \\
\hline & $2^{\text {nd }}$ & $5(19.2)$ & $6(26.1)$ & 0.734 \\
\hline & $3^{\text {rd }}$ & $6(23.1)$ & $2(8.7)$ & 0.254 \\
\hline & $4^{\text {th }}$ & $1(3.8)$ & $3(13.0)$ & 0.330 \\
\hline \multirow[t]{4}{*}{ Vomiting } & $1^{\mathrm{st}}$ & $3(11.5)$ & $0(0.0)$ & 0.237 \\
\hline & $2^{\text {nd }}$ & 7 (26.9) & $2(8.7)$ & 0.145 \\
\hline & $3^{\text {rd }}$ & 3 (11.5) & $1(4.3)$ & 0.612 \\
\hline & $4^{\text {th }}$ & $3(11.5)$ & $1(4.3)$ & 0.612 \\
\hline
\end{tabular}

${ }^{\mp}$ Pearson's Chi-square or Fisher's exact test was done as appropriate

$\left.\mathrm{kg} / \mathrm{m}^{2}, \mathrm{p}=0.021\right]$. On the other hand, both BMI and WC reduced in both study groups with $\mathrm{BMI} \geq 25$ $\mathrm{kg} / \mathrm{m}^{2}$ and the percentage changes of reduction [metformin $(n=12)$ vs. placebo $(n=13)$ : BMI: $7.77 \pm 8.35$ vs. $-1.33 \pm 2.44 \mathrm{~kg} / \mathrm{m}^{2}, p=0.024$; WC: $6.06 \pm 7.75$ vs. $-0.58 \pm 5.29 \mathrm{~cm}, p=0.049]$ were significantly higher in the metformin group.

Among the gastrointestinal adverse effects, only loose motion occurred significantly at a higher rate in metformin group [ $1^{\text {st }}$ follow up visit: $65.4 \%$ vs. $17.4 \%, p=0.001$ ] than placebo group. Other adverse effects were similar in rates in both groups. Frequency of loose motion and nausea improved in metformin group and abdominal pain reduced in placebo group with progression of time (Table-4).

\section{Discussion}

This randomized placebo controlled double blind study showed the beneficial effects of addition of metformin with lifestyle modifications on reduction of BMI and WC without causing significant sideeffects in patients with PCOS. We observed that metformin with lifestyle modification led to the reduction of BMI. Most of the studies found similar results and few studies also found that metformin reduced insulin resistance even without reducing BMI, in PCOS [22]. Pouliot et al. showed that higher WC is predictive of abnormal endocrine and metabolic function and is associated with increasing risk of cardiovascular disease [28]. In our study, the mean reduction of WC in metformin group was $2.81 \mathrm{~cm}$. Other investigators have also reported reduction of WC, though some reported no changes in WC after treatment with metformin $[17,29,30]$. We found that metformin, in combination with lifestyle changes, significantly reduced $\mathrm{BMI}$ and $\mathrm{WC}$ especially in obese patients. A recently published systematic review and metaanalysis of randomized controlled trials (RCTs) showed that metformin significantly reduced WC in PCOS patients [31].

In the present study, there was significant improvement of menstrual irregularity in both metformin and placebo groups. Therefore in the present study, it was not clearly possible to discriminate the impact of metformin on this issue as lifestyle modification was practiced by the 
participants of both groups. Improvement of menstrual cycle was found in metformin group in several other studies [29,30,32-34]. However, improvement observed in the placebo group indicated the role of lifestyle modification even without significant change in BMI. Some studies found higher regularization of menstrual cycle by modification of lifestyle than metformin alone. However, the combination therapy seemed to be better than the lifestyle therapy alone.

In the present study hirsutism improved in both metformin and placebo groups. However, we observed significantly greater decrease of $\mathrm{mFG}$ score in metformin compared to placebo group after 9 months of study period. The results indicated that metformin and lifestyle modification together had better effect on hirsutism rather than either one alone. Contrary to our findings, some studies reported lack of beneficial effect of metformin on hirsutism in PCOS [33,34]. However, those studies observed the effect of metformin on women with high baseline $\mathrm{mFG}$ score and for a period of only six months. The effect of metformin on the hair follicles to reduce the state of hirsutism might not be apparent if the treatment duration is below six months as the hair turnover cycle is more than three months. Therefore, it may not be possible to make any inference on the action of metformin in reducing hirsutism unless treatment for adequate period is provided.

As in our cases, improvement of acne in metformin group is also supported by observations of others $[32,35]$. There was no significant change of polycystic appearance of ovaries in either group after nine months of study period. However, ultrasonogram of ovaries lacked description of status of ovarian follicles.

Four women conceived during the study, three of which were in the placebo group and one in the metformin group. Assessment of impact of metformin on fertility probably requires a longer duration of follow-up. One study found that after six months of metformin therapy, menstrual regularity was achieved in $86 \%$ women and $50 \%$ were ovulatory at six months [36]. We also found significantly higher rate of ovulation in the metformin group. Costello and Eden, also found similar improvement in obese PCOS patients [37].
There were no serious adverse events in either the metformin or placebo group. However, metformin was associated with more minor gastrointestinal events. But, the adverse events gradually improved over time.

The main strength of this study was its randomized double blind placebo controlled design and its long duration. The study findings also illustrated the importance of life style modification in management of clinical manifestations of PCOS. In conclusion, the present study showed that metformin with lifestyle modifications had considerable favorable impacts on clinical manifestations, particularly in terms of androgenic activity, weight loss, WC, BMI, and menstrual irregularity in PCOS patients. Effect of metformin therapy on fertility of PCOS cases needs longer duration of follow-up.

\section{Acknowledgments}

We thank the members of the Department of Endocrinology of BSMMU for their support. We also acknowledge the technical support by the Microbiology, Radiology and Biochemistry departments of BSMMU.

\section{Authors' contributions}

$\mathrm{NA}, \mathrm{HB}$ and $\mathrm{MAH}$ designed the study protocol. NA, TS and $A B$ collected the data; NA, MSM, TS and $\mathrm{MAH}$ did the statistical analysis; NA, MSM, $A B$ and $\mathrm{HB}$ prepared the manuscript. $\mathrm{MAH}$ and $\mathrm{HB}$ supervised and coordinated the study and edited the manuscript. All authors read and approved the final manuscript.

\section{Competing interests}

None of the authors have any conflict of interest to declare.

\section{Ethics approval and consent to participate and publish}

Prior to commencement, the research protocol was approved by the Institutional Review Board (IRB) of BSMMU (No.BSMMU/2014/05). Informed written consent was taken from all participants to participate in the study and publish the study findings. 


\section{Funding}

We obtained a grant from Aristopharma Pharmaceutical Mfg. Ltd of Bangladesh.

\section{Reference}

1. Knochenhauer ES, Key TJ, Kahsar-Miller $M$, Waggoner W, Boots LR, Azziz R. Prevalence of the polycystic ovary syndrome in unselected black and white women of the southeastern United States: a prospective study. J Clin Endocrinol Metab. 1998; 83: 3078 - 3082.

2. Diamanti-Kandarakis $E$, Kouli $C R$, Bergiele $A T$, Filandra FA, Tsianateli TC, Spina GG, et al. A survey of the polycystic ovary syndrome in the Greek island of Lesbos: hormonal and metabolic profile. J Clin Endocrinol Metab. 1999; 84: 4006 - 4011.

3. Michelmore KF, Balen AH, Dunger DB, Vessey MP. Polycystic ovaries and associated clinical and biochemical features in young women. Clin Endocrinol (Oxf). 1999; 51: $779-786$.

4. Asuncion M, Calvo RM, San Millan JL, Sancho J, Avila S, Escobar-Morreale HF. A prospective study of the prevalence of the polycystic ovary syndrome in unselected Caucasian women from Spain. J Clin Endocrinol Metab. 2000; 85: $2434-2438$.

5. Azziz R, Woods KS, Reyna R, Key TJ, Knochenhauer ES, Yildiz BO. The prevalence and features of the polycystic ovary syndrome in an unselected population. J Clin Endocrinol Metab. 2004; 89: 2745- 2749.

6. March WA, Moore VM, Willson KJ, Phillips DI, Norman RJ, Davies MJ. The prevalence of polycystic ovary syndrome in a community sample assessed under contrasting diagnostic criteria. Hum Reprod. 2010; 25: 544- 551.

7. Moran LJ, Misso ML, Wild RA, Norman RJ. Impaired glucose tolerance, type 2 diabetes and metabolic syndrome in polycystic ovary syndrome: a systematic review and metaanalysis. Hum Reprod Update. 2010; 16: 347363.

8. Moran C, Tena G, Moran S, Ruiz P, Reyna R, Duque $X$. Prevalence of polycystic ovary syndrome and related disorders in Mexican women. Gynecol Obstet Invest. 2010; 69: 274280.

9. Chen $X$, Yang $D$, Mo $Y$, Li L, Chen $Y$, Huang $Y$. Prevalence of polycystic ovary syndrome in unselected women from southern China. Eur J Obstet Gynecol Reprod Biol. 2008; 139: 59-64.

10. Kumarapeli V, Seneviratne Rde A, Wijeyaratne CN, Yapa RM, Dodampahala SH. A simple screening approach for assessing community prevalence and phenotype of polycystic ovary syndrome in a semi-urban population in Sri Lanka. Am J Epidemiol. 2008; 168: 321- 328.

11. Yildiz BO, Bozdag G, Yapici Z, Esinler I, Yarali H. Prevalence, phenotype and cardiometabolic risk of polycystic ovary syndrome under different diagnostic criteria. Hum Reprod. 2012; 27(10): 3067-3073.

12. Apridonidze T, Essah PA, luorno MJ, Nestler JE. Prevalence and characteristics of the metabolic syndrome in women with polycystic ovary syndrome. J Clin Endocrinol Metab. 2005; 90(4): 1929-1935.

13. Lashen H. Role of metformin in the management of polycystic ovary syndrome. Ther Adv Endocrinol Metab. 2010; 1(3): 117128.

14. Ortega-González C, Luna S, Hernández L, Crespo G, Aguayo P, Arteaga-Troncoso G, et al. Responses of serum androgen and insulin resistance to metformin and pioglitazone in obese, insulin-resistant women with polycystic ovary syndrome. J Clin Endocrinol Metab. 2005; 90(3): 1360-1365.

15. Amin $\mathrm{M}$, Abdel-Kareem $\mathrm{O}$, Takekida $\mathrm{S}$, Moriyama T, Abd el-Aal G, Maruo T. Minireview: Up-date management of non responder to clomiphene citrate in polycystic ovary syndrome. Kobe J Med Sci. 2003; 49(3): 59-73.

16. Nestler JE. Metformin for the treatment of the polycystic ovary syndrome. N Engl J Med. 2008; 358(1): 47-54.

17. Velazquez EM, Mendoza S, Hamer T, Sosa F, Glueck CJ. Metformin therapy in polycystic ovary syndrome reduces hyperinsulinemia, 
insulin resistance, hyperandrogenemia, and systolic blood pressure, while facilitating normal menses and pregnancy. Metabolism. 1994; 43(5): 647-654.

18. Hoeger KM, Kochman L, Wixom N, Craig $\mathrm{K}$ Miller RK, Guzick DS. A randomized, 48-week, placebo-controlled trial of intensive lifestyle modification and/or metformin therapy in overweight women with polycystic ovary syndrome: a pilot study. Fertil Steril. 2004; 82(2): 421-429.

19. Moran LJ, Hutchison SK, Norman RJ, Teede HJ. Lifestyle changes in women with polycystic ovary syndrome. Cochrane Database Syst Rev. 2011; (7): CD007506.

20. Naderpoor N, Shorakae S, de Courten B, Misso ML, Moran LJ, Teede HJ. Metformin and lifestyle modification in polycystic ovary syndrome: Systematic review and metaanalysis. Hum Reprod Update. 2016; 21(5): 560-574.

21. Rotterdam ESHRE/ASRM-Sponsored PCOS Consensus Workshop Group. Revised 2003 consensus on diagnostic criteria and long-term health risks related to polycystic ovary syndrome. Fertil Steril. 2004; 81(1): 19-25.

22. Sharma N, Siriesha, Lugani $Y$, Kaur A, Ahuja VK. Effect of metformin on insulin levels, blood sugar, and body mass index in polycystic ovarian syndrome cases. J Family Med Prim Care. 2019; 8(8): 2691-2695.

23. Panidis D, Tziomalos K, Papadakis E, Vosnakis C, Chatzis P, Katsikis I. Lifestyle intervention and anti-obesity therapies in the polycystic ovary syndrome: Impact on metabolism and fertility. Endocrine. 2013; 44: 583-590.

24. World Health Organisation (WHO). The AsiaPacific perspective : redefining obesity and its treatment. Sydney: Health Communications Australia Pty Ltd. Feb 2000. p. 1- 56. Available at: https://apps.who.int/iris/handle/10665/206936.

25. Alberti KGMM, Eckel RH, Grundy SM, Zimmet $\mathrm{PZ}$, Cleeman JI, Donato KA, et al. Harmonizing the metabolic syndrome: $A$ joint interim statement of the international diabetes federation task force on epidemiology and prevention; National heart, lung, and blood institute; American heart association; World heart federation; International. Circulation. 2009; 120(16): 1640-45.

26. Escobar-Morreale HF, Carmina E, Dewailly $D$, Gambineri A, Kelestimur F, Moghetti $P$, et al. Epidemiology, diagnosis and management of hirsutism: A consensus statement by the androgen excess and polycystic ovary syndrome society. Hum Reprod Update. 2012; 18(2): 146-170.

27. Leiva $R$, Bouchard $T$, Boehringer $H$, Abulla $S$, Ecochard R. Random serum progesterone threshold to confirm ovulation. Steroids. 2015; 101: 125-129.

28. Pouliot MC, Després JP, Lemieux $S$, Moorjani $S$, Bouchard C, Tremblay A, et al. Waist circumference and abdominal sagittal diameter: best simple anthropometric indexes of abdominal visceral adipose tissue accumulation and related cardiovascular risk in men and women. Am J Cardiol. 1994; 73(7): 460-468.

29. Nazari T, Bayat R, Hamedi M. Metformin therapy in girls with polycystic ovary syndrome: a self-controlled clinical trial. Arch Iran Med. 2007; 10(2): 176-181.

30. Morin-Papunen LC, Koivunen RM, Ruokonen A, Martikainen HK. Metformin therapy improves the menstrual pattern with minimal endocrine and metabolic effects in women with polycystic ovary syndrome. Fertil Steril. 1998; 69(4):691-696.

31. Guan $Y$, Wang $D, B u H$, Zhao $T$, Wang $H$. The Effect of Metformin on Polycystic Ovary Syndrome in Overweight Women: A Systematic Review and Meta-Analysis of Randomized Controlled Trials. Int J Endocrinol. 2020; 2020: 5150684.

32. Kazerooni T, Dehghan-Kooshkghazi M. Effects of metformin therapy on hyperandrogenism in women with polycystic ovarian syndrome. Gynecol Endocrinol. 2003; 17(1): 51-56.

33. Kelly CJ, Gordon D. The effect of metformin on hirsutism in polycystic ovary syndrome. Eur $J$ Endocrinol. 2002; 147(2): 217-221. 
34. Moghetti $P$, Castello R, Negri C, Tosi F, Perrone $F$, Caputo $M$, et al. Metformin effects on clinical features, endocrine and metabolic profiles, and insulin sensitivity in polycystic ovary syndrome: a randomized, double-blind, placebo-controlled 6-month trial, followed by open, long-term clinical evaluation. J Clin Endocrinol Metab. 2000; 85(1): 139-146.

35. Sharma S, Mathur DK, Paliwal V, Bhargava P. Efficacy of Metformin in the Treatment of Acne in Women with Polycystic Ovarian Syndrome:
A Newer Approach to Acne Therapy. J Clin Aesthet Dermatol. 2019; 12(5): 34-38.

36. Zafar S. Role of metformin in correcting hyperinsulinemia, menstrual irregularity and anovulation in polycystic ovary syndrome. $J$ Ayub Med Coll Abbottabad. 2005; 17(4): 54-56.

37. Costello MF, Eden JA. A systematic review of the reproductive system effects of metformin in patients with polycystic ovary syndrome. Fertil Steril. 2003; 79(1): 1-13. 